\title{
PEMBERIAN PELAYANAN JASA KEPADA MASYARAKAT: DESAIN DAN RAB GOA MARIA GEREJA ST. MIKHAEL, KAMPUNG KWEEL, MERAUKE
}

\section{Giving Service To The Community: The Design \& Budget and Cost Plansof Maria Cave In St. Mikhael Church, Kweel Village, Merauke}

\author{
Yashinta Irma Pratami Hematang ${ }^{1)^{*}}$, Yosehi Mekiuw ${ }^{2)}$ \\ ${ }^{1)}$ Fakultas Teknik Universitas Musamus \\ ${ }^{2)}$ Fakultas Pertanian Universitas Musamus
}

Article history

Received: Jul 24, 2020;

Accepted: Okt 23, 2020

* Corresponding author:

E-mail:

yashinta@unmus.ac.id

DOI: https://doi.org/

10.46549/igkojei.v2i1.127

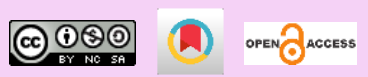

\begin{abstract}
Prayer activities, specifically for Catholics, are carried out through the Virgin Mary at a certain pilgrimage area. The Catholic Church of St. Michael in Kweel Village has a problem in planning for the construction of Maria Cave. As a form of Higher Education Tri Dharma, activities are carried out to provide cave design services along with the preparation of Budget and Cost Plans (RAB). The methods of implementing the activities include site/site data collection, analysis, drafting of design concepts, drawings, and ending with the making of the RAB. The result of the activity is the design of a Maria Cave measuring 8 X $5 \mathrm{~m}$ without roofing with geometric shapes consisting of public and private zones with the concept of utility lighting and resulting in building cost calculation with a value of $R p .42,900,000$.
\end{abstract}

Keywords: Pilgrimage; Orison; Catholic Christianity

\section{ABSTRAK}

Kegiatan-kegiatan doa secara khusus bagi umat katolik adalah dengan melalui perantara Bunda Maria, pada suatu kawasan ziarah. Gereja Katolik St. Mikhael di Kampung Kweel memiliki permasalahan dalam perencanaan pembangunan Goa Maria. Sebagai salah satu bentuk Tri Dharma Perguruan Tinggi, maka dilakukan kegiatan pemberian pelayanan jasa desain goa dan penyusunan Rencana Anggaran dan Biaya (RAB). Metode pelaksanaan kegiatan meliputi: pengumpulan data site/tapak, analisis, penyusunan konsep desain, drawing, dan diakhiri dengan pembuatan RAB. Hasil kegiatan adalah desain suatu bangunan Goa Maria berukuran 8 X 5 m tanpa pernanungan dengan bentuk geometris yang terdiri atas zona publik dan privat dengan konsep utilitas pencahayaan lampu dan juga menghasilkan perhitungan biaya pembangunan goa maria dengan nilai bangunan adalah Rp. 42.900.000.

Kata kunci: Ziarah; Doa; Kristen Katolik

\section{PENDAHULUAN}

Negara Indonesia dalam Undang-Undang Dasar 1945 memberi jaminan kepada warga negaranya untuk memeluk agama dan kepercayaannya, serta beribadat sesuai keyakinannya. Begitu pula umat katolik yang beribadah memanjatkan doa kepada Tuhan. Menurut (Christimoty, 2019), bagi orang Kristen ibadah kepada Allah adalah penting dan perlu bagi kehidupan bergereja. Selanjutnya Nugroho 
(2000) mengungkapkan bahwa dengan melakukan kegiatan-kegiatan religius, manusia dapat merasa terbantu kehidupan sehari-harinya. Kegiatan-kegiatan doa secara khusus bagi umat katolik adalah dengan melalui perantara Bunda Maria, pada suatu kawasan ziarah. Sehingga Goa Maria menjadi salah satu tempat memanjatkan doa yang penting bagi umat katolik.

Mitra pengabdian yaitu Gereja Katolik St. Mikhael di Kampung Kweel berada di daerah pedalaman berjarak sekitar $170 \mathrm{~km}$ atau kurang lebih 4 jam perjalanan dengan kendaraan mobil dari daerah perkotaan Merauke (Distrik Merauke). Selain keadaan geografis yang jauh dari kota, terdapat permasalahan dalam perencanaan pembangunan Goa Maria Gereja St. Mikhael Kampung Kweel, khusunya dalam rencana anggaran belanja.

Kementerian Pekerjaan Umum dan Perumahan Rakyat (2016) menjelaskan bahwa pembangunan suatu bangunan meliputi beberapa komponen biaya diantaranya: biaya pelaksanaan konstruksi, biaya perencanaan teknis, biaya pengawasan teknis/manajemen konstruksi dan biaya pengelola kegiatan. Kegiatan pengabdian kepada masyarakat ini fokus pada aspek pembiayaan perencanaan. Tujuan dari PKM ini adalah mendesain Goa Maria Kampung Kweel dan menyusun RAB (Rencana Anggaran dan Biaya) desain tersebut.

\section{METODE}

Kegiatan dilaksanakan di dua lokasi, yaitu di lokasi tapak/site rencana pembangunan goa maria. Pada tapak ini dilakukan pengukuran dan pengamatan agar dapat dilakukan analisa dan penyusunan konsep. Lokasi kedua dilaksanakan di studio/laboratorium gambar Jurusan Arsitektur Universitas Musamus Merauke. Di dalam studio, dilakukan proses gambar perancangan kegiatan pengabdian ini. Untuk waktu pelaksanaan adalah di bulan Februari-Maret tahun 2019. Kegiatan berlangsung selama dua bulan (8 minggu) dengan perincian: 1 minggu pengamatan/observasi tapak, 2 minggu penyusunan konsep, 3 minggu perancangan gambar, dan 2 minggu pembuatan RAB.

Teknik pengumpulan data adalah secara kuantitatif dan kualitatif. Kuantitatif yaitu dengan pengukuran data tapak rencana pembangunan goa maria. Secara kualitatif yaitu dengan wawancara dengan jemaat/umat sehingga keinginan jamaat dapat diakomodir dalam desain. Untuk analisis data yaitu dengan membuat analisa tapak dan analisa konsep zonasi ruang dan dilakukan analisa konsep bentuk/geometris, serta konsep utilitas goa.

Analisa hasil desain yaitu dengan menjelaskan analisa tapak, analisa zonasi ruang dan kegiatan, dan analisa konsep desain. Konsep desain dianalisa berdasarkan analisa geometris dan analisa utilitas goa. Selanjutkan juga dilakukan proses analisa perhitungan RAB goa. 


\section{HASIL DAN PEMBAHASAN}

\section{HASIL DESAIN}

\section{A. HASIL ANALISA TAPAK}

Tapak berukuran dimensi $8 \mathrm{~m} \mathrm{X} 5 \mathrm{~m}$ berbentuk persegi panjang. Untuk pencahayaan goa dibuat terbuka/tanpa pernaungan pada sisi berdoa karena mengandalkan cahaya matahari (pencahayaan alami) serta penghawaan alami. Pernaungan hanya diaplikasikan pada area patung Bunda maria dan area letak lilin-lilin sembahyang (Gambar 1).
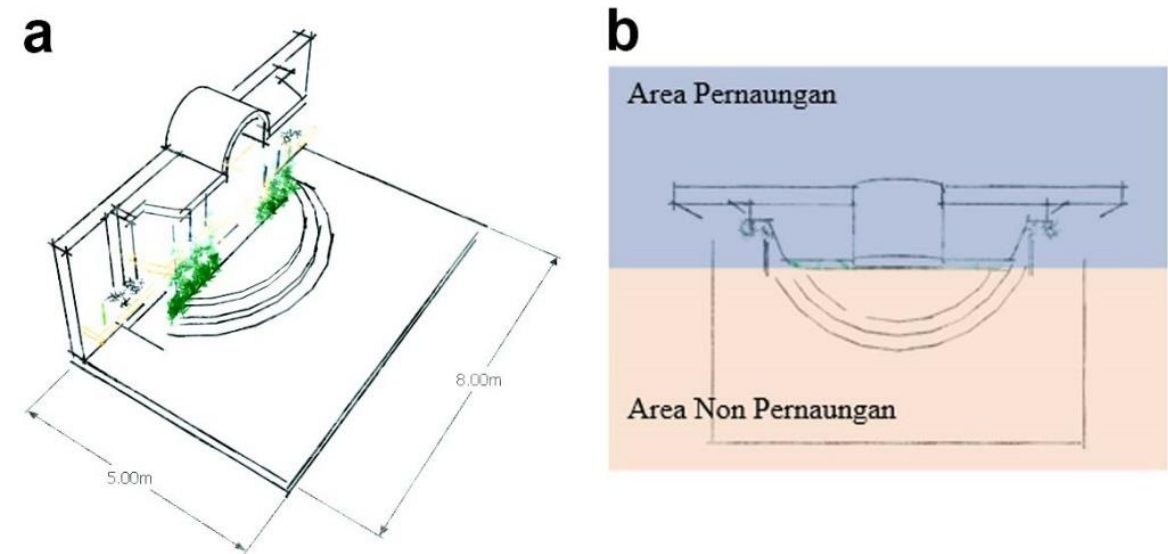

Gambar 1. Hasil analisa tapak (a) Dimensi tapak Goa Maria; (b) Pernaungan tapak Goa Maria (pencahayaan dan penghawaan Alami). (sumber: analisa pribadi, 2019).

\section{B. HASIL ANALISA ZONASI}

Hasil analisa zonasi adalah berdoa (individu dan berkelompok), menyalakan lilin, mencuci tangan dan muka. Seperti diuraikan oleh Nugroho (2000), bahwa kegiatan-kegiatan yang dilakukan pengunjung Goa Maria antara lain dengan ibadat dan berdoa, baik oleh sekelompok remaja, dewasa, orang tua maupun anak-anak. Pengunjung percaya cara ini membuat mereka merasa semakin dekat dengan Tuhan dan mengembangkan iman mereka. Oleh karena itu, zonasi dibagi menjadi zona publik sekaligus privat (Gambar 2). Zona publik dimana area tersebut dapat dikunjungi oleh berbagai kalangan masyarakat yang ingin berdoa dan zona privat dalam artian bahwa setiap pengunjung secara pribadi dapat memanjatkan doanya di pelataran tempat doa. 


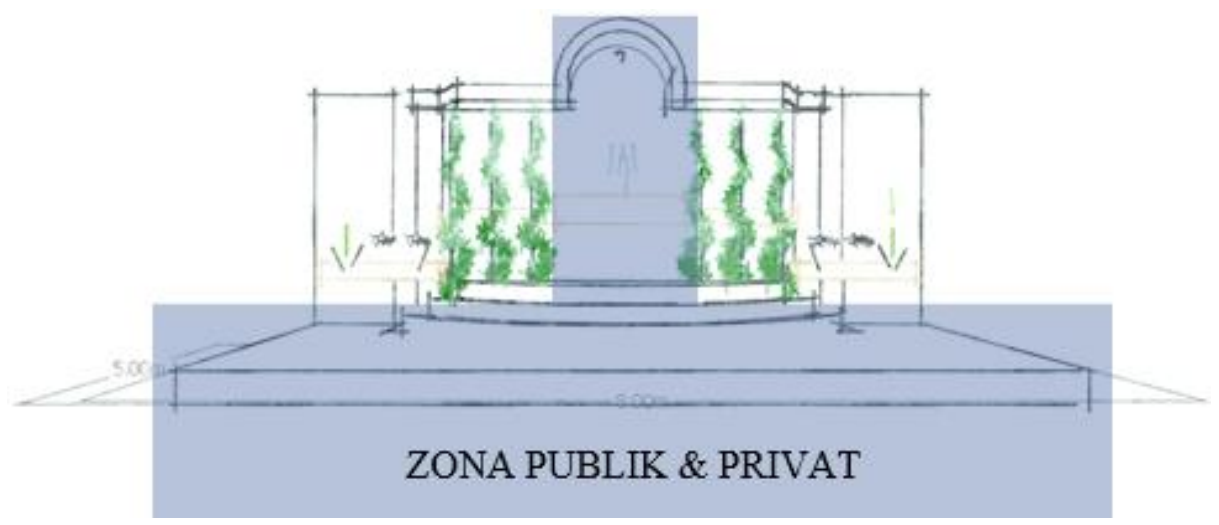

Gambar 2. Zona publik dan privat Goa Maria. (sumber: analisa pribadi, 2019).

Zona publik adalah merupakan area/zona yang bisa dimasuki oleh semua orang. Zona ini memiliki letak pada area yang sering dilewati oleh banyak orang oleh sebab itu sebaiknya tidak sulit dalam hal aksesibilitas. Sedangkan zona privat adalah zona yang terbatas, dimana pelaku yang menggunakan ruang itu hanya yang memiliki akses saja (Irawan, 2015).

\section{HASIL ANALISA KONSEP}

\section{c.1. Bentuk/geometris}

Secara keseluruhan elemen pembentuk ruang gereja (lantai, dinding, dan plafon), banyak menerapkan bentuk-bentuk geometris simetris (Gambar 3). Geometris simetris dilambangkan sebagai kesempurnaan/keagungan Tuhan dalam hal hubungan keseimbangan dengan umatNya. Selain itu, juga memiliki makna sebagai kestabilan, sifat yang dapat diandalkan, ketenangan, dan kekokohan, yang merupakan sifat-sifat perlindungan yang dicari oleh manusia. Lalu kemudian ruang ibadah juga dapat memiliki penonjolan pola geometri pada plafon. Hal ini mengandung prinsip bahwa kebesaran, keagungan, dan penghormatan kepada Tuhan Yang Maha Esa sebagai peran utama. Struktur plafon yang mengarah dan menuju ke atas juga memiliki orientasi vertikal membuat lambang perwujudan bangunan gereja yang diwujudkan sebagai rumah Tuhan. Hal ini merupakan makna penghayatan kepada Tuhan. Selain itu, juga membantu dalam menciptakan suasana agung (Wardani, 2006). 


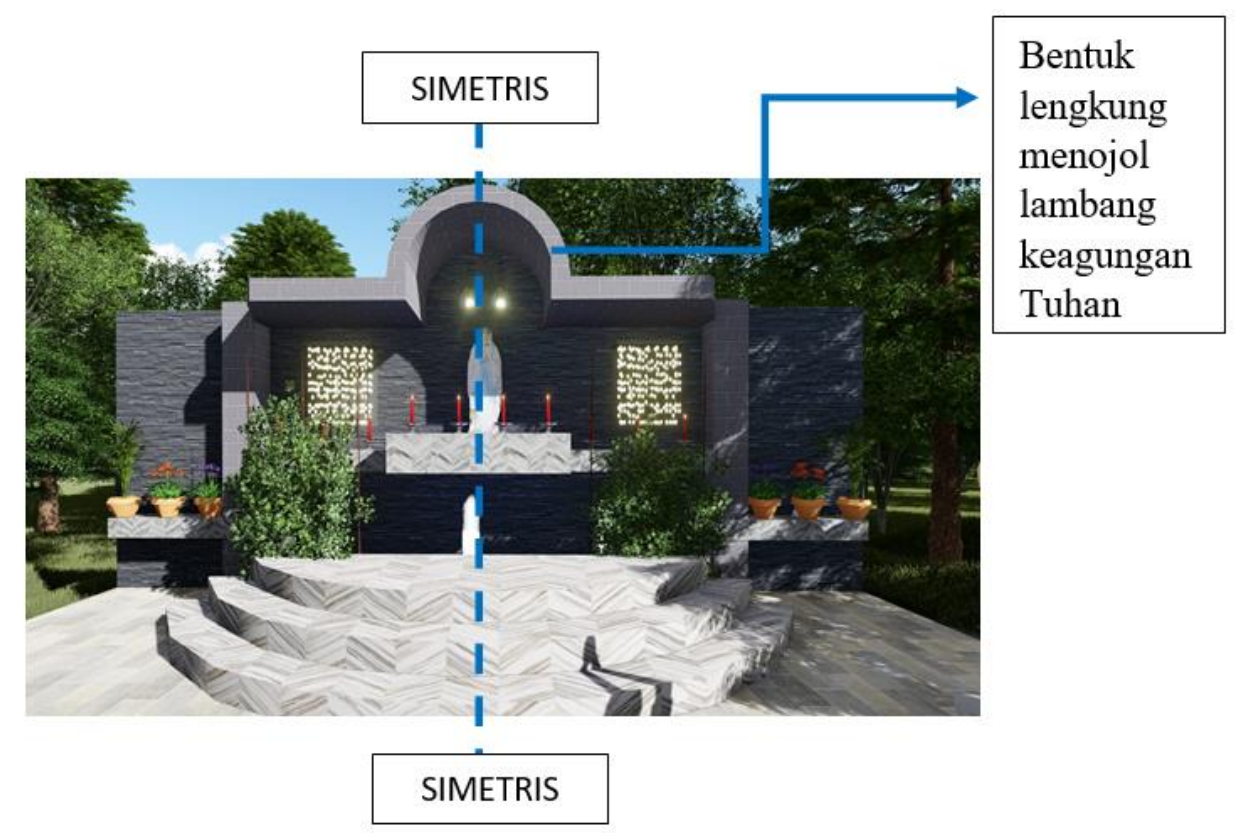

Gambar 3. Konsep bentuk/geometris Goa Maria. (sumber: analisa pribadi, 2019).

\section{c.2. Konsep utilitas}

Utilitas goa yang juga sekaligus menjadi konsep dari goa adalah tentang pencahayaan lampu (Gambar 4). Jenis lampu yang digunakan adalah jenis LED menjuntai secara vertikal dan jenis pencahayaan titik yaitu dengan lampu sorot dengan warna kuning.
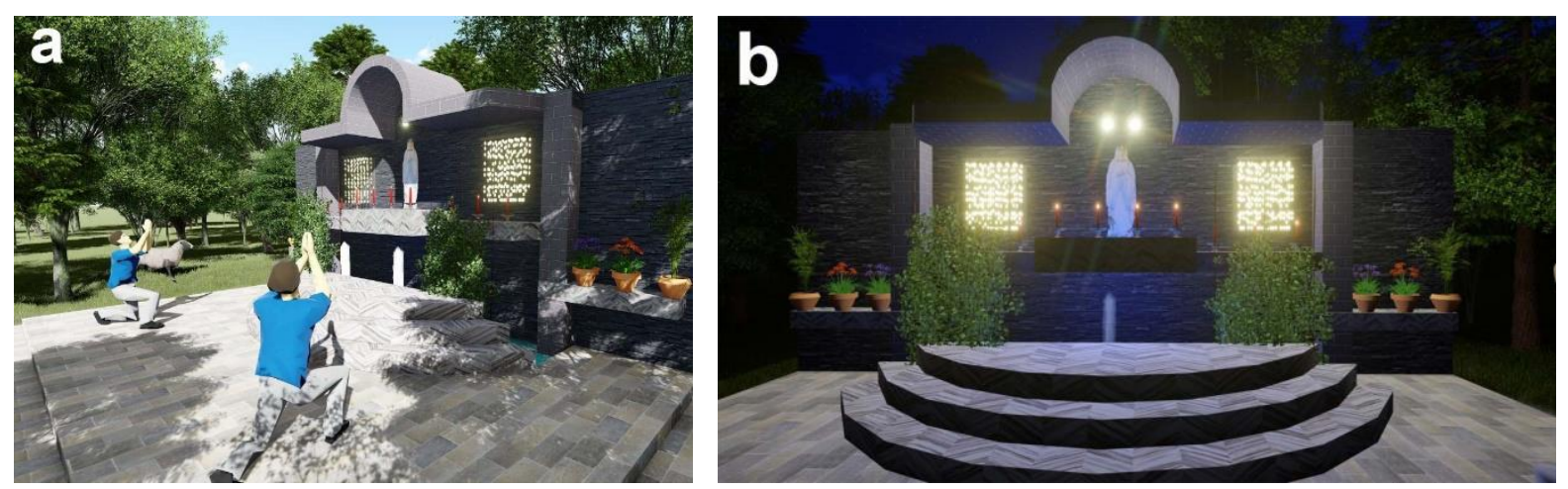

Gambar 4. Konsep utilitas. (a) Utilitas cahaya pada Goa Maria; (b) Utilitas lampu Goa Maria. (sumber: analisa pribadi, 2019).

Utilitas pencahayaan dapat dikatakan baik jika mata kita dapat melihat obyek-obyek dengan jelas, nyaman, dan baik juga tidak menimbulkan bayang-bayang. Untuk sumber pencahayaan, dapat secara alami yaitu dari sinar matahari dan secara buatan dapat berasal dari lampu. Pada saat malam hari ataupun cuaca mendung, perlu diupayakan pencahayaan buatan dari lampu (Romadhon, 2009). 


\section{HASil PENYUSUnAN RENCANA ANGGARAN DAN BiAYA}

Berikut adalah rekapitulasi pekerjaan Goa Maria Kampung Kweel dengan analisa harga satuan tahun 2019.

Tabel 1. Rencana Anggaran dan Biaya Goa Maria Kweel Tahun 2019

\begin{tabular}{|c|c|c|}
\hline No. & Uraian & Jumlah Harga \\
\hline 1 & $\mathrm{Um} \mathrm{u} \mathrm{m}$ & 2.500 .000 \\
\hline 2 & Pekerjaan tanah & 5.273 .172 \\
\hline 3 & Pekerjaan pondasi dan dinding & $3.747 .005,49$ \\
\hline 4 & Pekerjaan plesteran & $3.035 .333,75$ \\
\hline 5 & Pekerjaan beton & $18.417 .220,90$ \\
\hline 6 & Pekerjaan pintu,kunci dan kaca & 0,00 \\
\hline 7 & Pekerjaan plafond & 0,00 \\
\hline 8 & Pekerjaan penutup lantai & $6.218 .650,98$ \\
\hline 9 & Pekerjaan sanitasi & 0,00 \\
\hline 10 & Pekerjaan pengecatan & 770.448 .25 \\
\hline 11 & Pekerjaan elektrikal & $2.930 .900,00$ \\
\hline 12 & Pekerjaan atap & 0,00 \\
\hline A. & Real coast & $42.892 .731,37$ \\
\hline B. & Ppn $10 \%$ & \\
\hline D. & Jumlah $a+b$ & \\
\hline E. & Biaya perencanaan & \\
\hline $\mathrm{F}$. & Biaya pengawasan & \\
\hline G. & Biaya tpp & \\
\hline H. & Total keseluruhan & $42.892 .731,37$ \\
\hline I. & Dibulatkan & 42.900.000,00 \\
\hline
\end{tabular}

\section{Terbilang : Empat Puluh Dua Juta Sembilan Ratus Ribu Rupiah}

\section{KESIMPULAN}

Terciptanya desain Goa Maria Kampung Kweel dengan konsep perancangan terdiri dari: analisa tapak, analisa zonasi, analisa bentuk/geometris, dan analisa utilitas. Diperoleh Rencana Anggaran dan Biaya pembangunan Goa Maria Kampung Kweel.

\section{UCAPAN TERIMA KASIH}

Ucapan terima kasih kami sampaikan kepada mitra kegiatan pengabdian yaitu Gereja Katolik St. Mikhael Kampung Kweel Merauke.

\section{DAFTAR PUSTAKA}

Christimoty DN. 2019. Teologi Ibadah dan Kualitas Penyelenggaraaan Ibadah: Sebuah Pengantar, PASCA: Jurnal Teologi dan Pendidikan Agama Kristen. 15(1): 1-7.

Irawan JD. 2015. Perancangan Sekolah Internasional Pekanbaru Dengan Pendekatan Eko Arsitektur. JOMFTEKNIK. 2(1):73-80.

Kementerian Pekerjaan Umum dan Perumahan Rakyat. 2016. Modul 5: Biaya Pembangunan 
Bangunan Gedung Negara.

Kementerian Riset Teknologi dan Pendidikan Tinggi. 2019. Pedoman Operasional Penilaian Angka Kredit Kenaikan Jabatan Akademik/Pangkat Dosen.

Nugroho AD. 2000. Pengembangan Goa Maria Kaliori Banyumas (Penekanan desain arsitektur organik).

Romadhon IF. 2009. Evaluasi Kualitas Penerangan dan Penentuan Letak Lampu Serta Jenis Lampu Pada Ruangan Teknik Universitas Negeri Semarang, Program Studi S1 - Teknik Elektro.

Wardani LK. 2006. Simbolisme Liturgi Ekaristi Dalam Gereja Katolik Sebuah Konsepsi dan Aplikasi Simbol. DIMENSI INTERIOR 4(1): 17-24. 